\title{
Mathematical Approach for the Determination of the Surface Roughness in the Milling of Poly-Ether-Ether-Cethone (PEEK)
}

\author{
M. P. Calvo-Correa ${ }^{1}$, C. J. Cortés-Rodríguez ${ }^{2}$, Julián R. Camargo L. ${ }^{3}$ \\ ${ }^{1}$ Mechanical Engineering Faculty, Universidad Nacional de Colombia, Bogotá, Colombia \\ ${ }^{2}$ Mechanical Engineering Faculty, Universidad Nacional de Colombia, Bogotá, Colombia \\ ${ }^{3}$ Engineering Faculty, Universidad Distrital Francisco José de Caldas, Bogotá, Colombia
}

Received Date : December 30, 2021 Accepted Date : January 27, 2022 Published Date : February 07, 2022

\begin{abstract}
This research aims to determine the behavior of the surface roughness parameters $\mathrm{Ra}, \mathrm{Rq}$ and $\mathrm{Rz}$ in the milling of poly-ether-ether-ketone PEEK, in terms of the machining variables: cutting speed feed rate and the machining strategy. To solve this problem, a response surface study was made with a central design composed of three replicates per point to obtain a surface equation that determines the expected roughness value based on the velocity values of Cutting speed and fate rate.
\end{abstract}

This model was repeated for each machining strategy analyzed: Raster and Spiral. To find the correct values of Rq and Rzin, the manufacturer could find desirable values; it could be for minor friction pieces or better shape forms. This investigation found that the value of $\mathrm{Rq}$ and $\mathrm{Rz}$ in milling machining with a Raster and Spiral trajectory increases with increasing feed rate and decreasing with cutting speed. Likewise, it was observed that the Raster technique obtains higher roughness values than by Spiral.

Key words: Machining, PEEK, Raster, Spiral, Surface roughness

\section{INTRODUCTION}

Polyether ether ketone (PEEK) is a two-phase thermoplastic polymer composed of ether and ketone aromatic chains, is stable at temperatures up to $300{ }^{\circ} \mathrm{C}$, is resistant to chemical damage and radiation, is compatible with different reinforcing materials such as fiberglass and carbon [1]-[3].

This material is widely used in the aerospace, automotive, electronics and medical industries.
Among the main applications that have this are the manufacture of bearings, parts of pistons, cymbals of compression valves, compression rings, and insulation of cables. Its use in the manufacture of implants includes implants of the hip, knee, buffer boxes, and others [4]-[7].

The surface roughness in a material is the mark that the cutting tool leaves on the piece when it is machined, this depends on the type of tool with which it is machined and parameters such as the cutting speed and the advance of the same [8]-[10].

The rugosity study currently has different purposes such as lubrication, load capacity, tool life, corrosion resistance, fatigue resistance, noise reduction, and other important applications [9], [11].

The roughness can be evaluated by measuring different parameters [12].

Arithmetic average roughness: $\mathrm{Ra}$ is the arithmetic mean of the deviations concerning the average line of profile, this rugosity value is the one that is most often used in the surface study. The roughness $\mathrm{Ra}$ is determined with (1).

$$
\mathrm{Ra}=1 L \int|(x)-m| d x
$$

Average depth between ten points: $\mathrm{Rz}$ is the average value of the differences between the five highest and the lowest points. It can be calculated using (2):

$$
\mathrm{Rz}=15(Z 1+Z 2+Z 3+Z 4+Z 5)
$$

Quadratic mean roughness: $\mathrm{Rq}$ is the square root of the mean of the squares of the ordinates of the profile about the mean line of measurement. The roughness Rq can be determined by (3). 
M. P. Calvo-Correa et al., International Journal of Emerging Trends in Engineering Research, 10(2), February 2022, 80 - 84

$$
\mathrm{R} q=\sqrt{1 \mathrm{~L} \int \mathrm{y} 210 \mathrm{dx}}
$$

The surface roughness in the milling of material is mainly influenced by the cutting parameters such as the cutting speed, the advance of the cutting tool, the type of tool and the type of tool trajectory [13].

Parameters such as Ra Roughness do not fully describe the topography of the surface since it describes an arithmetic average that omits the values of the highest or lowest peaks, thus resulting in an adequate average but a surface unfit for the suggested purpose of cellular adaptation. For this reason, more robust parameters such as $\mathrm{Rq}$ and $\mathrm{Rz}$ must be described [14]-[15].

In this article, the value of the variables $\mathrm{Rq}$ and $\mathrm{Rz}$ was determined mathematically depending on the variables cutting speed and feed speed for two different machining techniques: Raster and Spiral.

This is to provide a tool to the manufacturer to evaluate how the necessary parameters should be at the machining to obtain a certain roughness.

To determine the mathematical behavior of the desired variables, an experimental response surface design was used.

\section{METHODS AND MATERIALS}

This investigation aims to determine the behavior of the surface roughness $\mathrm{Rq}$ and $\mathrm{Rz}$ in the machining of the PEEK concerning the variables of machining cutting speed, the advance and the cutting trajectory.

In this research, the machining method used was milling. To achieve this task, the roughness obtained by different values of feed speed, cutting speed and selected trajectories were evaluated.

In this work, two types of trajectories were evaluated: Spiral and Raster. For each of these trajectories, the same machining parameters were evaluated. The experimental design used was a response surface design (RSM) of six central points.

For the elaboration of this experimental design, concave and convex specimens of the same radius were elaborated, which were machined with the same parameters and the same number of replicas for each chosen trajectory, the combinations of the factors were the same for each machining technique and all the other machining parameters used were constant in the preparation of the specimens.
For machining, the same tool was used, a spherical tip insert with two cutting edges, the same insert holder and the same $\mathrm{CNC}$ machine were used, in this way, it was sought that no other element, except those that were wanted to evaluate, would influence in the answers obtained.

The material used for the research is PEEK KETRON 1000, which is a thermoplastic without reinforcements. The machining was done using a $\mathrm{CNC}$ v-20i milling machine.

The tool used to machine the specimens was an interchangeable copying insert KDMB06M0ERLDK115M. The insert is made of an uncoated premium quality carbide grade, designed for high edge wear resistance in non-ferrous materials, iron and cast iron.

\section{RESULTS}

The exploration points described in Figure 1 were considered for the elaboration of the respective response surfaces.

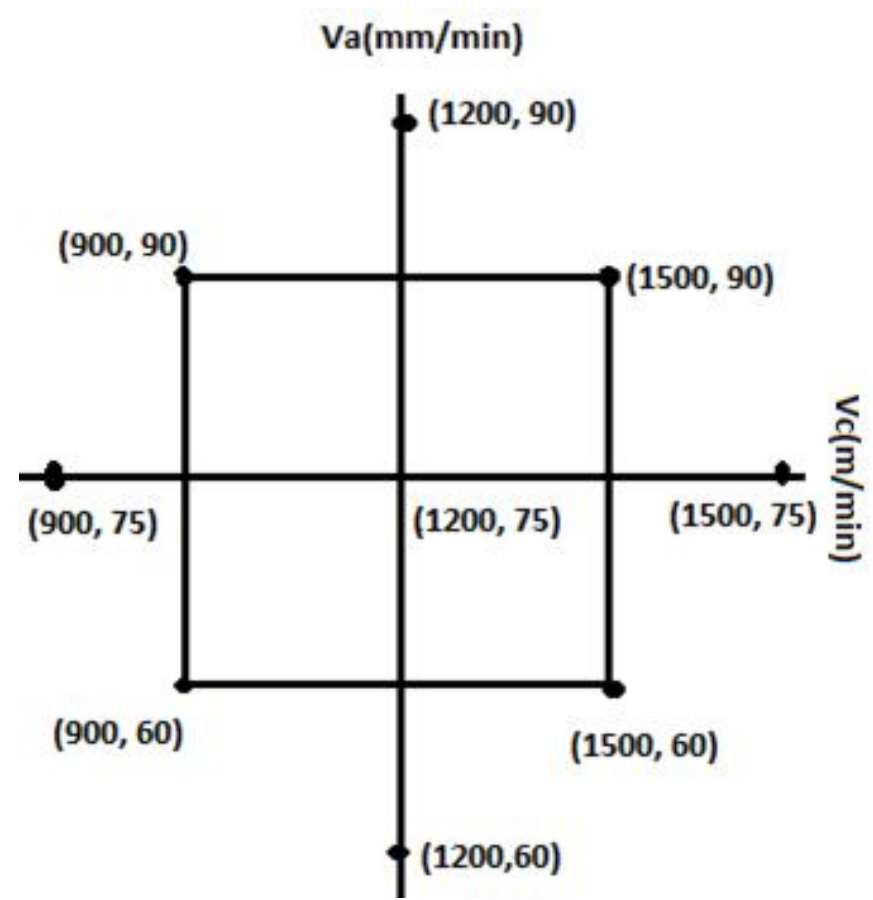

Figure 1: Points of the central composite design for the response Surface

This same distribution was used for each path to be evaluated. Next, the response surfaces obtained for each technique are related.

\subsection{Spiral Technique Analysis}

In Error! Reference source not found. and Error! Reference source not found., the response surfaces obtained for the roughness parameters $\mathrm{Rq}$ and $\mathrm{Rz}$, respectively, are observed. 
Equations 4 and 5 of each behavior are obtained in terms of advance and cut speed variables.

Regarding the behavior of $\mathrm{Rq}$ and $\mathrm{Rz}$ for the spiral trajectory, equations (4) and (5) respectively, it is observed that both parameters depend on the factors of advance and cutting speed, the parameter $\mathrm{Rq}$ is influenced by the combination of the factors, in comparison to $\mathrm{Rz}$ that does not depend on the combination of the same, in the same way, both parameters are affected by the square of the factors.

From Error! Reference source not found. and Error! Reference source not found., it is observed that the value of the roughness $\mathrm{Rq}$ and $\mathrm{Rz}$ increases as the advance increases and when the cutting speed decreases.

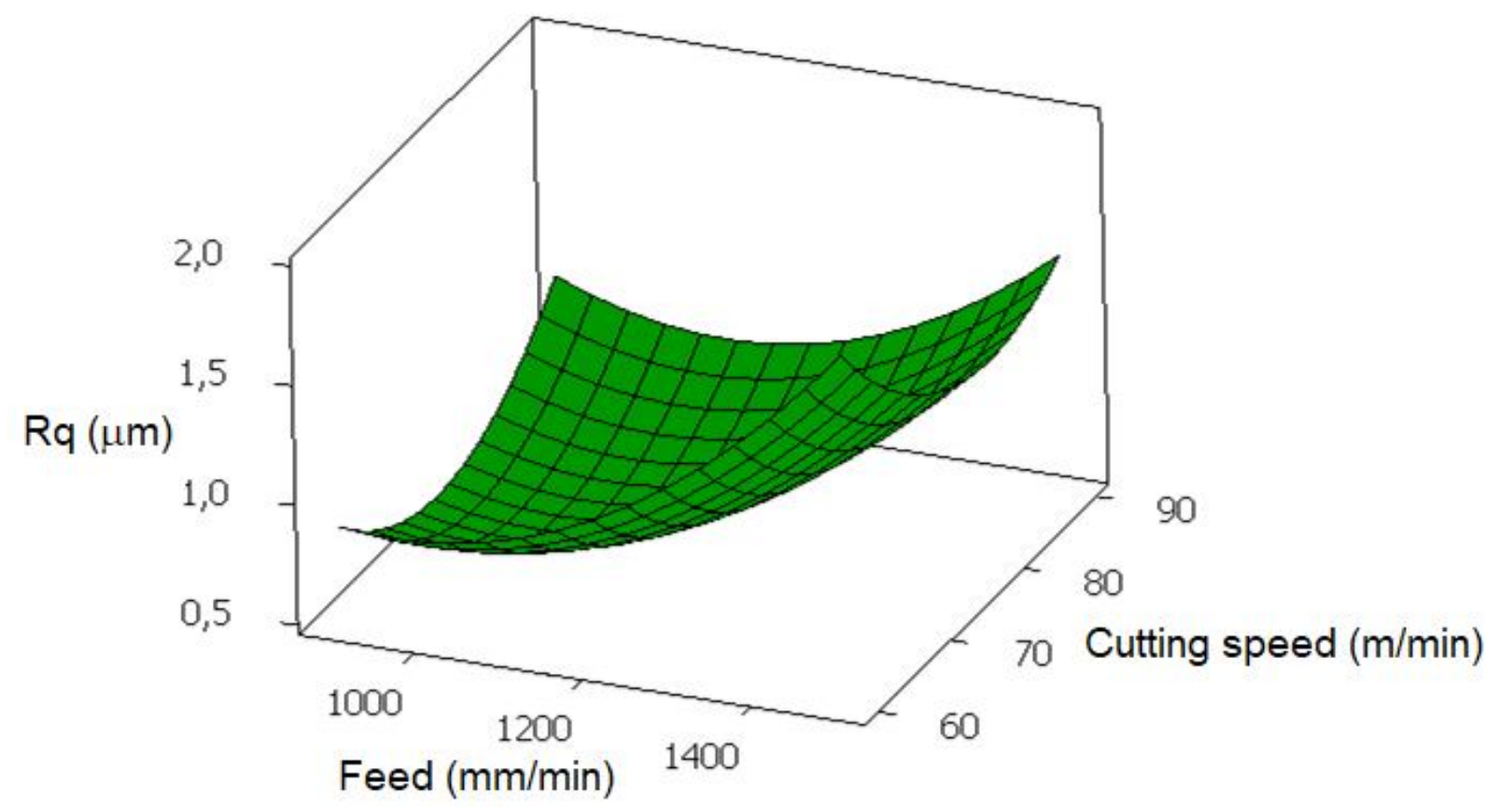

Figure 2: Response surface of Rq for the Spiral technique

$\mathrm{Rq}=10,30-0,005 \mathrm{Va}-0,19 V c+3,66 \times 10^{6} \mathrm{Va}^{2}+0,0015 V c^{2}-0,3472 \times 10^{6} \mathrm{VcVa}$

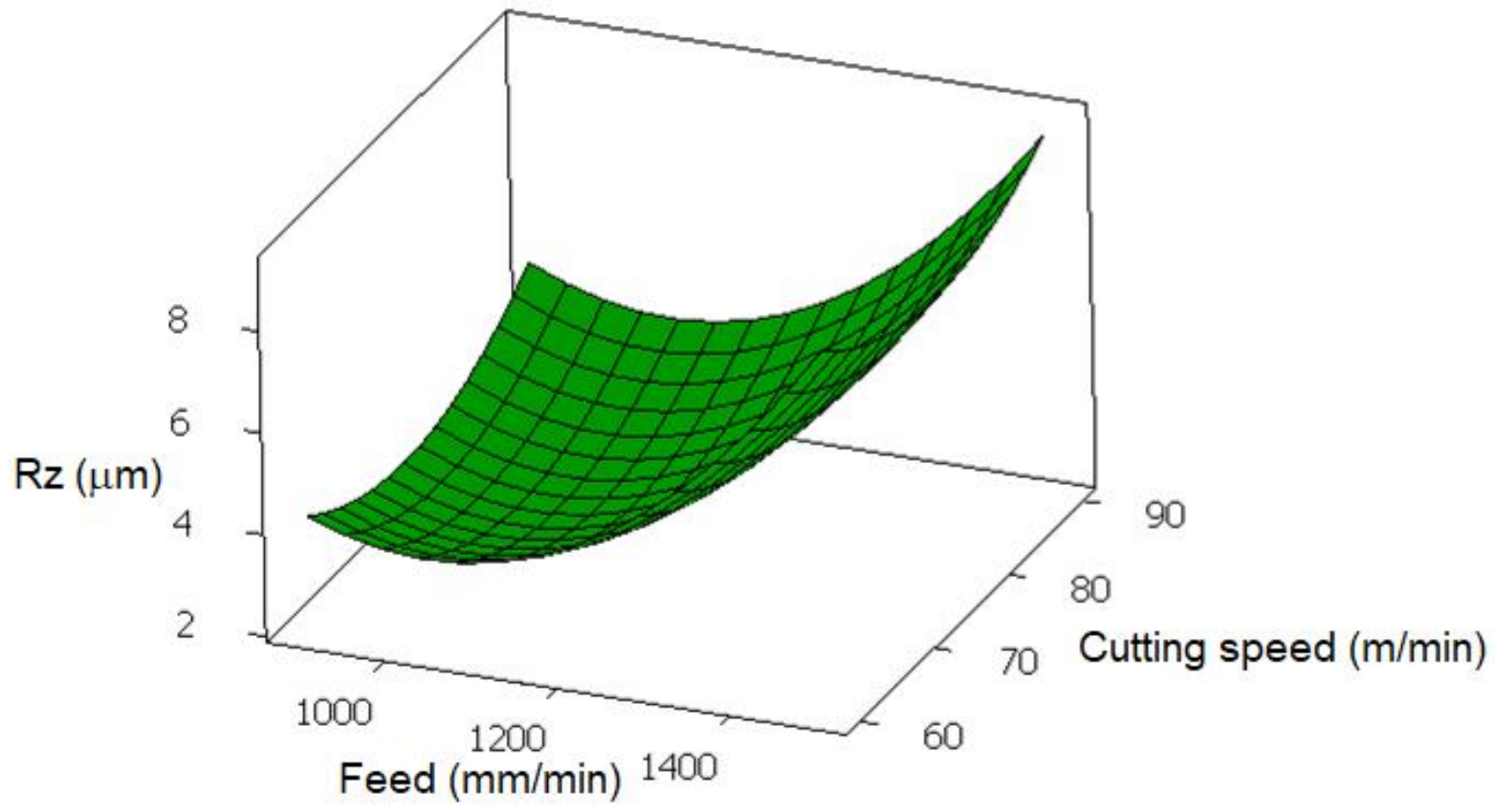

Figure 3: Response surface of $\mathrm{Rz}$ for the Spiral technique

$\mathrm{Rz}=53,88-0,049 \mathrm{Va}-0,68 \mathrm{Vc}+0,0049 V c^{2}+0,250 \times 10^{6} \mathrm{Va}^{2}$ 


\subsection{Raster Technique Analysis}

From (6) and (7), it can be determined that the roughness $\mathrm{Rq}$ and $\mathrm{Rz}$ are linearly influenced by the variables cutting speed, feed, and the square of them but not by the combination of these factors.
From the response surfaces obtained, Figure 1 and Figure 2, it is observed that increasing the advance significantly increases the $\mathrm{Rq}$ and $\mathrm{Rz}$ roughness. Likewise, the response surfaces obtained for $\mathrm{Rq}$ and $\mathrm{Rz}$ do not clearly show the influence of the cutting speed on the surface roughness, when optimizing the response surface, it is observed that when the cutting speed decreases, the surface roughness increases.

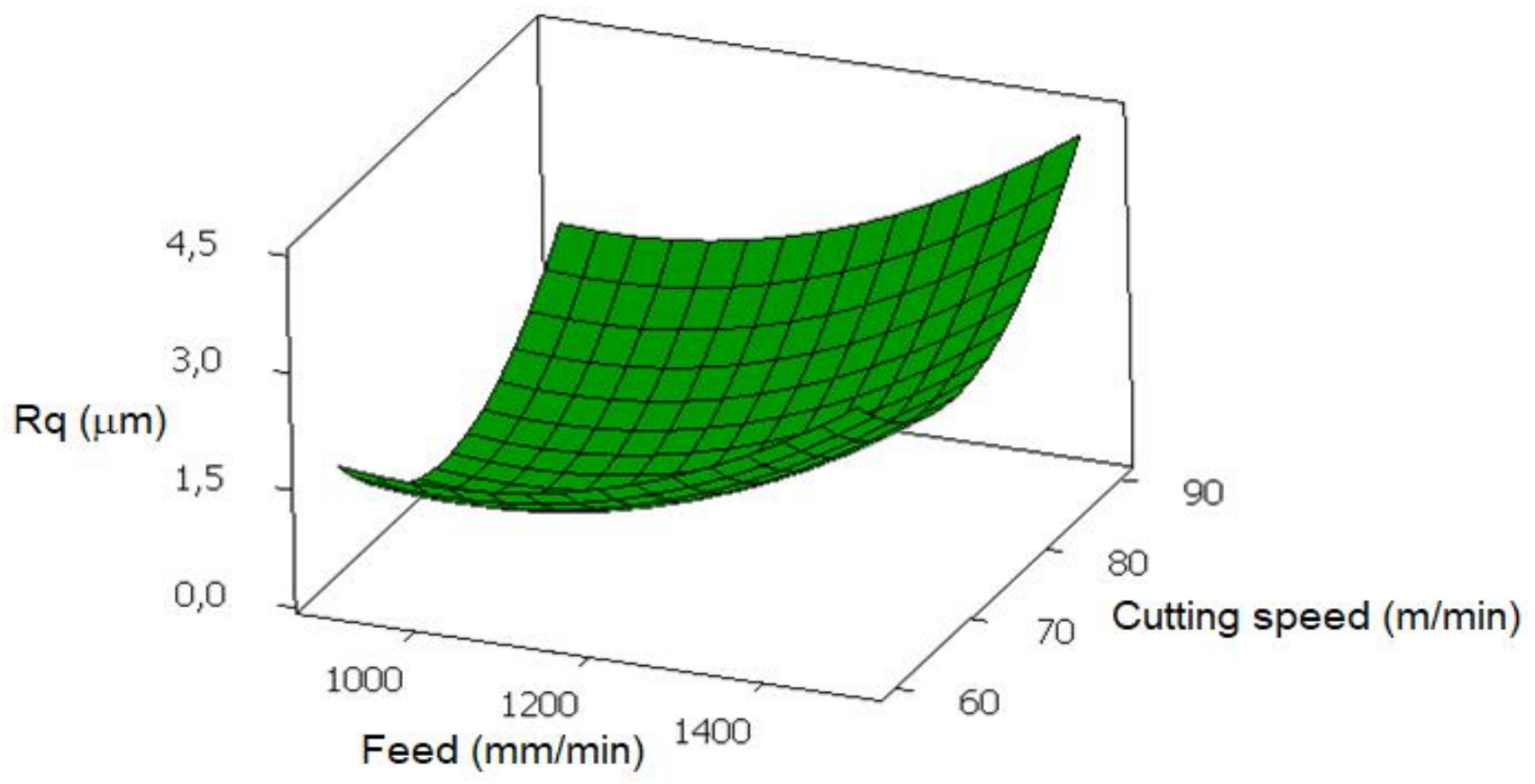

Figure 1: Response surface of $\mathrm{Rq}$ for the Raster technique

$\mathrm{Rq}=40,87-0,014 V a-0,90 V c+0,006 V c^{2}+7,4862 \times 10^{-6} V a^{2}$

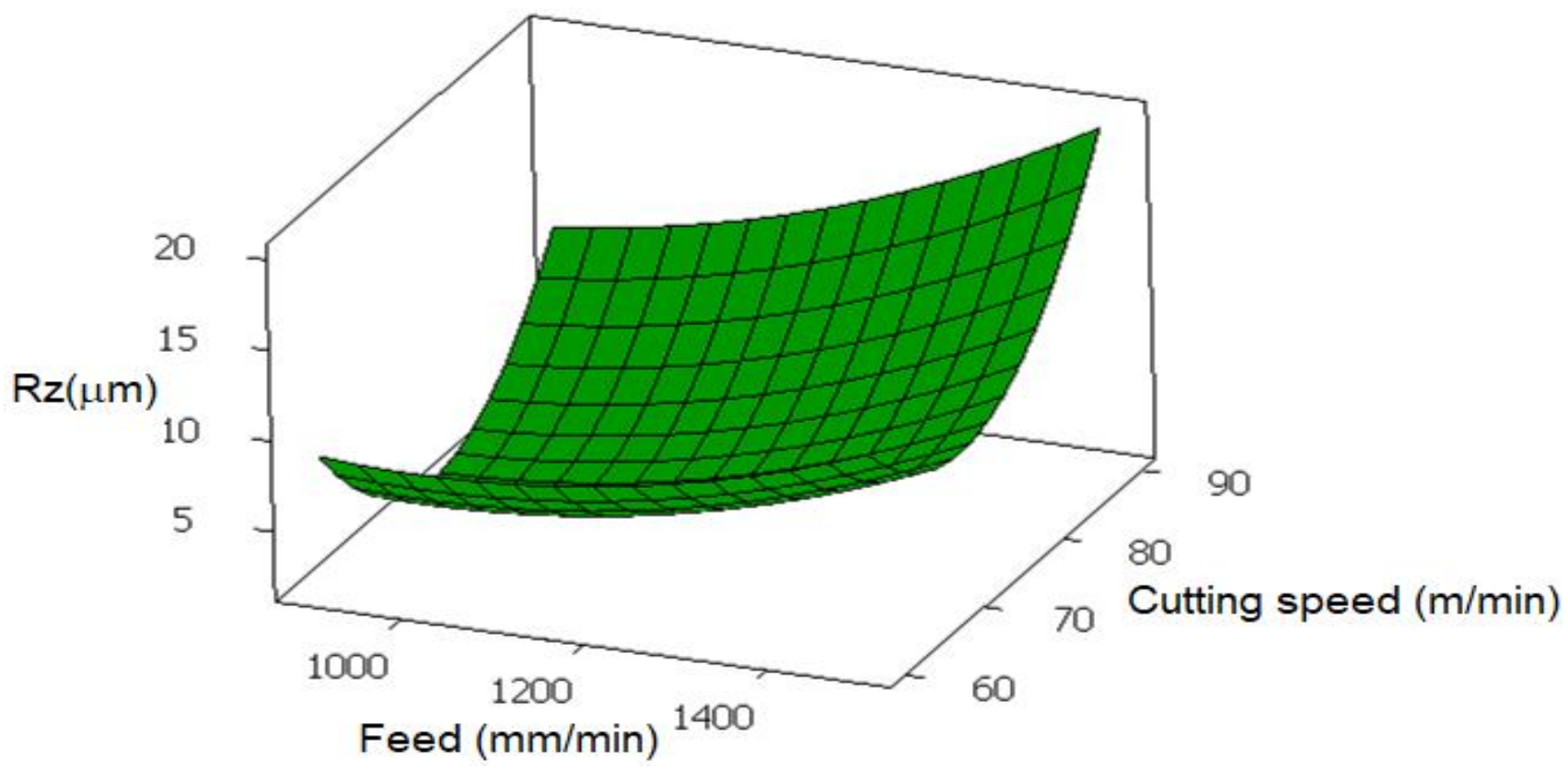

Figure 2: Response surface of $\mathrm{Rz}$ for the Raster technique

$\mathrm{Rz}=214,13-0,056 \mathrm{Va}-5,03 V c+0,188 \times 10^{6} V a^{2}+0,03 V c^{2}$ 


\section{CONCLUSIONS}

Regarding the behavior of the surface roughness, it is observed that Rq and Rz are affected directly by the cutting speed and the advance, so increasing the advancement and decreasing the cutting speed increases the roughness.

On the other hand, the variables $\mathrm{Rq}$ and $\mathrm{Rz}$ for both trajectories are affected by both parameters and their square parameters in a linear manner and not by the combination of their factors.

When analyzing the graphs of the roughness values that can be obtained for each combination of parameters, it was observed that with the Raster technique, higher roughness values are obtained than with the Spiral technique, this means that in the manufacturing process of the PEEK, in cases which applications need to have a small surface roughness, it is recommended to use the Spiral manufacturing technique with low advances and high cutting speeds.

\section{ACKNOWLEDGMENTS}

The authors would like to thank the Universidad Nacional de Colombia, Universidad Distrital Francisco José de Caldas and the Universidad Distrital Francisco José de Caldas LASER research group that supported the development and testing of the project.

\section{REFERENCES}

1. ASTM F2778-09. Standard Test Method for Measurement of Percent Crystallinity of Polyetheretherketone (PEEK) Polymers by Means of Specular Reflectance Fourier Transform Infrared Spectroscopy (R-FTIR), ASTM International, West Conshohocken, PA, 2015.

2. S. Kurtz. PEEK Biomaterials Handbook, Elsevier, 2012.

3. J. Wu, L. Li, C. Fu, F. Yang, Z. Jiao, X. Shi and P. Zhang. Micro-porous polyetheretherketone implants decorated with BMP-2 via phosphorylated gelatin coating for enhancing cell adhesion and osteogenic differentiation, Colloids and Surfaces B: Biointerfaces, vol. 169, pp. 233-241, 2018.

4. U. Bruder. High-Performance Polymers, In User's Guide to Plastic, Carl Hanser Verlag, Munich, 2015.

5. M. Rinaldi, T. Ghidini, F. Cecchini, A. Brandao, and F. Nanni. Additive layer manufacturing of poly (ether ether ketone) via FDM, Composites Part B: Engineering, vol. 145, pp. 162-172, 2018.

6. J. Ortega-Martínez, M. Farré-Lladós, J. Cano-Batalla and J. Cabratosa-Termes. Polyetheretherketone (PEEK) as a medical and dental material. A literature review. Medical Research Archives, vol. 5, no. 4, 2017.
7. S. Najeeb, M. S. Zafar, Z. Khurshid and F. Siddiqui. Applications of polyetheretherketone (PEEK) in oral implantology and prosthodontics, Journal of Prosthodontic Research, vol. 60, no. 1, pp. 12-19, 2016.

8. E. Budak, E. Ozturk and L. T. Tunc. Modeling and simulation of 5-axis milling processes, CIRP Annals Manufacturing Technology, vol. 58, no. 1, pp. 347-350, 2009.

9. O. Çolak, C. Kurbanoğlu and M. C. Kayacan. Milling surface roughness prediction using evolutionary programming methods, Materials and Design, vol. 28, pp- 657-666, 2007.

10. G. Wang, Y. Wan, B. Ren and Z. Liu. Fabrication of an orderly micro/nanostructure on titanium surface and its effect on cell proliferation, Materials Letters, vol. 212, pp. 247-250, 2018.

11. M. Sedlaček, B. Podgornik and J. Vižintin. Influence of surface preparation on roughness parameters, friction and wear, Wear, vol. 266, pp. 482-487, 2009.

12. E. S. Gadelmawla, M. M. Koura, T. M. A. Maksoud, I. M. Elewa and H. H. Soliman. Roughness parameters, Journal of Materials Processing Technology, vol. 123, pp. 133-145, 2002.

13. Precision Devices, Inc. Surface Roughness Terminology and Parameters, Op Parameter Definitions, Precision Devices, Inc. 606 County Street . P.O. Box 220 - Milan, M. 48160. pp. 3974-3975, 2013.

14. N. A. Feidenhans'L, P. E. Hansen, L. Pilný, M. H. Madsen, G. Bissacco, J. C. Petersen and R. Taboryski. Comparison of optical methods for surface roughness characterization, Measurement Science and Technology, vol. 26, no. 8, pp. 1-10, 2015.

15. M. Galati, P. Minetola and G. Rizza. Surface Roughness Characterisation and Analysis of the Electron Beam Melting (EBM) Process, Materials, vol. 12, 2211, 2019. 